\title{
J(৫)
}

Received: 21.04 .2019

Accepted: 01.06.2019

Published: 24.06 .2019

JOTS, 3/2, 2019: 451-470

\section{Dede Korkut Kitabında Sıfat-Fiilli Tamlama Grupları ve Bunların Aktarımı Üzerine*}

\section{On the Participle Constructions in the Book of Dädä Qorqut and Their Translations}

\author{
Sultan TULU \\ ( Muğla / T urkey) \\ E-mail: sultantulu@yahoo.com
}

In the Dädä Qorqut Book, the verbal adjective $\{-A n+d A\}$ construction was read as a gerund. However, in some cases this does not reflect the context of the text. In fact, this adjective verb or participle is not associated with the particle dA. The article improves the topic $\{-A n+D a\},\{-A r+D a\},\{-D u q+D a\}$. The structures accepted as gerunds were discussed in various editions of Dädä Qorqut. Repair suggestions were made there, where as a participle construction should be considered.

Key Words: the book of Dädä Qorqut, participle constructions, $\{-A n+D a\},\{-$ $\mathrm{Ar}+\mathrm{Da}\},\{-\mathrm{Duq}+\mathrm{Da}\}$, the particle $\mathrm{dA}$

Makale, Turkologentag 2016 (Hamburg Üniversitesi, Almanya) sempozyumunda sunulan bildirinin yeniden gözden geçirilmiş hâlidir. 


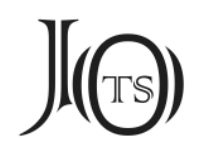

\section{Giriş}

Dede Korkut Hikâyeleri, Türk dili tarihi araştırmaları için vazgeçilmez bir kaynaktır. Arap alfabesi ile yazılan bu Oğuzname'de geçen kelimeler, deyimler, dilbilgisi özellikleri dilcilerin dikkatini çekmiş ve bulunduğu tarihten bu yana Dede Korkut metinlerinin okunması ve okuma problemleri üzerinde birçok araştırma ve yayın yapılmıştır. Ancak bunlarda hâlâ çözümlenmemiş okuma, anlamlandırma ve aktarma sorunları bulunmaktadır.

Dede Korkut metinleri, Dresden ve Vatikan olmak üzere iki nüshaya dayanmaktadır. Dresden nüshası harekesiz metin olup giriş bölümü yanında on iki boy içerir. Vatikan nüshası harekelidir ve giriş bölümü ile altı boy içerir. Her iki nüshanın dil özellikleri, dil tarihi bakımından bir tabakalaşma evresinden geçmiş olduğunu göstermektedir. Bu durum, söz konusu okuma sorunlarının çözümünü güçleştirmiştir. Buna rağmen metinlerde, eskicil (arkaik) özellikler yanında Eski Anadolu Türkçesi, Azerbaycan Türkçesi, Doğu ve Güneydoğu Anadolu ağız özellikleri dikkati çekmektedir. Bu son özellik Eski Anadolu Türkçesinde gelişen ve tarihî dönemden günümüze uzanan aynı bölgede konuşulan ağızları oluşturmaktadır.

Dede Korkut'ta okunma sorunlarının farklı sebepleri vardır. Bunlardan biri de metinlerdeki yazım özellikleri ve yazım yanlışlarıdır. Bunların bir kısmı yazıcıdan ya da anlatıcı ozanlardan kaynaklanmaktadır. Çünkü ozanlar ezberledikleri metinleri sözlü olarak icra ediyorlardı. Yazıcılar bunları yazıya geçirirken kendi dil/ağız özellikleri yanında anlatıcı ozanların yanlışlarını da yazıya geçirmiş olmalıdır. Bunun dikkate alınması, metnin bazı sorunlarının çözülmesi ve doğru anlaşılması bakımından önem taşır (Özçelik 2016/I: 48-50).

Dede Korkut metinlerinde $\{+\mathrm{dA}\}$ eki ile genişletilerek oluşmuş birleşik zarffiilli birimler/gerundiumlar, yani $\{-\mathrm{AndA}\}$ ve $\{$-ArdA $\}$ şekilleri günümüze dek yazıldığı gibi okunmuştu. Ancak kimi örneklerde metnin bağlamını yansıtmadığı için, $a$ ünlem edatının bitişik yazıldığı gibi, buna bir türlü anlam verilememişti. Hâlbuki bu dA, sıfat-fiile eklenen bitişik yazılan bir edattan başka bir şey değildir. Konu ile ilgili bazı araştırmacılar bu yapıya işaret ettikleri hâlde, Dede Korkut'un Türkçeye uyarlamalarında/aktarımında henüz tam bir birlik görülmemektedir. 


\section{$J(\Theta)$}

Makalede, Dede Korkut metinlerinde şimdiye dek birleşik zarf-fiil eki ya da partisipli gibi kabul gören $\{-A n d A\},\{-A r d A\},\{-d U k d A\}$ gibi yapılar, ERGiN, TEZCAN, ÖzçELıK gibi Dede Korkut araştırmacılarının yayınlarında gözden geçirildi ve sıfatfiilli/partisipli tamlama grubu olması gereken yerlere tamir önerileri getirildi. Sıfat-fiil/partisip olduğu düşünülen yapılarda $d A$ edatını zarf-fiilden farklı olduğunu göstermek için tire (-) işareti kullanıldı. Kimi örneklerde, birleşik zarf görünümünde olan birimler hem sıfat-fiil hem de zarf-fiil gibi her iki şekilde anlaşılmaktadır. Çünkü manzum olarak söylendiğini düşündüğümüz bu dizelerin devamında \{-An\} yanı sıra, \{-iken\}'li zarf-fiilli yapıların takip etmesi bize bunu düşündürmektedir. Bunlara aşağıda değinilecektir.

\section{Sıfat-fiilli/Partisipli Tamlama Grupları}

Sıfat-fiiller fiil kök ve gövdelerine getirilen eklerle yapılırlar. Eklendikleri fiile geçmiş zaman, geniş zaman, gelecek zaman anlamı verebilirler. Cümle içinde sıfatın kullanıldığı her yerde kullanılabilirler. Sıfat tamlaması kurabilirler, sıfatlar gibi ismin hâl ve çekim eklerini alarak adlaşabilirler. Cümlede isim oluşları da sıfatların isim olmaları gibi niteledikleri ismin söylenmemesi sonucu gerçekleşir. Sıfat-fiillerin, girişik-birleşik cümlelerde yan cümlenin yüklemi olabilme, edatlara bağlanarak zarf görevini üstlenme, hâl ekleriyle kalıplaşarak zarf-fiil eki olma özellikleri de vardır (Üstüner 2000: 21, 22).

Ancak Dede Korkut Kitabı'nda geçen bazı zarf-fiil görünümündeki şekiller aslında sıfat-fiilli tamlama grubu olarak nitelendirilmelidir. Bundan ötürü biz aşağıda $\{-A n+d A\},\{-A r+d A\},\{-d I k+d A\}$ ve $\{-d U k+d A\}$ şekillerini şimdiye dek okunan ve yorumlanan şekillere katkı olması açısından yeniden değerlendirmek istiyoruz.

\section{3. $\{-\mathrm{An}\}$ ve dA Edatı ile Kurulan Sifat-Fiilli Tamlama Grubu}

ERGiN, \{-AndA\} ekini Dede Korkut Kitabı'nda gerundiumlar altında gösterirken onun aslında bir partisip lokatifi olduğunu ama gerundium hâline gelmek yolunda olduğunu söyler. Bugün Azerî Türkçesinin bir özelliği olarak, Türkiye Türkçesinde kullanılan \{-IncA\} zarf-fiili yerine kullanılmaktadır (Ergin 2009/II: 468). Dede Korkut'ta \{-An\}'lı sıfat-fiil grubunun kullanılışı dikkati çekmektedir. 


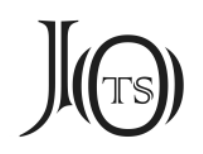

Eserde bu sıfat-fiil grubunun bugünkünün aksine fâille kullanıldığı, böylece \{dUk\} sıfat-fiil ekli isim tamlamasının yerini tuttuğu görülüyor: oglan emen 'oğlanın emdiği', hak yanduran 'Hakk'ın yaktığı', kızlar oturan 'kızların oturduğu', baya tutan gerdege 'bana tuttuğu gerdeğe' örneklerinde olduğu gibi. Bugün Azerî Türkçesinin belirli bir özelliği olan bu şeklin Dede Korkut'ta görülmesi oldukça önemlidir.

\{-An\}'ın lokatif şeklinin zarf-fiilleşmesi de bu fâilli sıfat-fiil grubu kullanışına dayanmaktadır. Yani fâilli \{-An\} sıfat-fiil grubu, bulunma hâli eki alınca zarffiil manası ortaya çıkmaktadır (Ergin 2009/II: 475-476).

Azerî Türkçesinde ve bazı Anadolu ağızlarında görülen $\{-(\mathrm{y}) \mathrm{An}+\mathrm{dA}\}$ zarf-fiil eki, \{-(y)An\} sıfat-fiil eki ile bulunma hâli eki \{+dA\}'nın kalıcı olarak birleşmesinden doğmuştur, yani $\{-g A n\}$ sifat-fiil eki ve $\{+d A\}$ bulunma durumu ekinden oluşmuştur. Eklendiği fiillere ayrıca '-dığı zaman', '-dığında' anlamını katar. \{-AndA\} zarf-fiil eki Türkiye Türkçesine gelinceye kadar kullanımdan düşmüştür. Bu zarffiil eki, açık bir şekilde zamanda eşitlik anlamı taşır. Ancak, Dede Korkut Kitabinda geçen bazı ifadelerin $\{(\mathrm{y}) \mathrm{An}\}+\mathrm{dA}\}$ zarf-fiil ekiyle aynı şekilde yazılmasını zamanda eşitlik işleviyle bağdaştırmak güçtür. DAşDEMir konuya açıklık getirmek için şu dizeleri örnek göstermiştir (2001: 61-62) ${ }^{1}$ :

berü gelgil başum bahtı évüm tahtı
évden çıkup yöriyen-de selvi boylum
topuğunda sarmaşan-da kara saçlum
kurılu yaya benzer çatma kaşlum
koşa badem sığmayan tar ağılum
güz almasına benzer al yanaklum
kavunum viregüm döleğüm! (Drs.8a/8-11)

DAŞDEMIR, yöriyende ve sarmaşanda sözcüklerindeki \{-AndA\} eki zarf-fiil olarak değerlendirildiğinde haklı olarak mantık dışı bir önermeyle karşılaşıldığına işaret eder, çünkü servi boylu olma niteliği evden çıkıp yürümeye, kara saçlı olma niteliği de saçın topuk üzerinde kıvrılmasına bağlı değildir. Burada geçen \{AndA\} ekini zarf-fiil eki olarak görmek mümkün değildir. \{-(y)An\} sıfat-fiil eki ve

1 Buradaki örnekler için Özçelik 2016'dan yararlandık. 


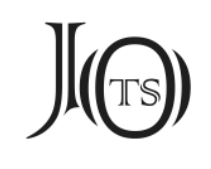

$d A$ edattır. Bundan dolayı bu biçim birimlerin içinde yer aldığı ifadeler zaman tümleci değil, niteleme blokları (=sıfat-fiilli tamlama grupları) olarak değerlendirilmelidir (2001: 63-64). Bu tür ifadelerde tamlayan/niteleyen kısım sıfat-fiil ya da sıfat, tamlanan/nitelenen kısım ise isim ya da bir başka tamlama olabilir. Örneğin, topuğunda sarmaşan kara saçlım gibi.

Bu durumda metin en doğru şu şekilde uyarlanmalıdır:

Beri gel başımın bahtı, evimin tahtı,

evden çıııp yürüyen selvi boylum,

topuğunda sarmaşan kara saçlım,

kurulu yaya benzer çatma kaşlım,

çift badem sığmayan dar ă̆ızlım,

güz almasına benzer al yanaklım,

kavunum, vireğim, döleğim!

Dede Korkut üzerinde çalışan araştırmacıların bir kısmı da zaten sadeleştirilmiş metinlerde bu tür ifadelerin geçtiği yerlerde -metin zarf-fiil ile ifade edilemeyeceğinden- sıfat-fiilli tamlama gruplarına başvurmuşlardır. Örneğin, aşağıdaki metnin ilk dizesi araştırmacılar tarafından şöyle sadeleştirilmiştir:

tavla tavla bagglanan-da atum-a yazux

qarțaş [déyü] șaqlayan-da ${ }^{2}$ yoldaşum-a yazux

yumrıg̉unda ${ }^{3}$ țalbınan-da şāhin quşum-a yazux

y1(l)tar ${ }^{4}$ ile țutan-da (țazum-a) yazux

béglige țoymadın ${ }^{5}$ özüm-e yazux

2 ÖzçeLiK sıklayanda.

3 Vat. 89a/9-10'a göre yumrig்umda.

4 Okuyanlar şimdiye dek Drs'de yeter, Vat'da harekeli yiter okunacak şekilde yazılan kelimeyi öyle okumuş, yll(l)tar okuyuşunu ilk kez TEZCAN önermiştir. (2001: 136). ÖzçELiK, onun bu tamirine katılmaktadir (2016/I: 380-381).

5 ÖzçELiK, Drs.82a/10'a dayanarak țoymadum okumuştur: Beglige țoymadum yigitlige ușanmadum (2016/I: 381-382). 


\section{$J(\Theta)$}

yiğitliğe ușanmadın ${ }^{6}$ cānum-a yazux,

dedi. (Drs.30a/4-8)

“Tövle-tövle bağlanan atlarımdan héyf!” (Zeynalov-Elizade 1988: 146); “Tavla tavla bağlanan atıma yazık!" (Kudret 1988: 42; Miyasoğlu 1999: 60); "Tavla tavla bağlanan atlarıma yazlk! (Boratav 1983: 97; Daşdemir 2001: 62-64)

Bu durumda metin günümüz Türkçesine kanımızca en doğru şöyle uyarlanmalıdır:

“Tavla tavla bağlanan atlarım-a yazık!

Kardeş (diye) inleyen yoldaşım-a yazık!

Yumruğumda çırpınan şahin kuşum-a yazık!

Tasma ile tutulan (tazım-a) yazık!

Beyliğe doymayan özüm-e yazık!

Yiğitliğe usanmayan canım-a yazık!"

Dede Korkut'ta bu tür ifadeler, -özellikle manzum olan kısımlarda- sözdizimsel paralelizm şeklinde kendini gösterir. Söz konusu sıfat-fiilli tamlama gruplarının geçtiği aşağıdaki dizelere paralel olarak sonraki 4. ve 5. dizelerde yine tamlama gruplarının, -bu defa $d A$ edatı olmadan- gerçek anlamda arka arkaya kullanıldığını görürüz: ${ }^{7}$

Qayțabanum güden-de sarvanum-mısın?

Qazaquçım ${ }^{8}$ güden-de 1 lqı̧̧ım-mısın?

Aǵ-ayılum güden-de çobanum-mısın?

6 ÖzçELik, Drs. 82a/10'a dayanarak ușanmadum okumuştur. (2016/I: 381-382) Ayrıca, Vat.89a/10'da uṣanmadum ve doymadum şeklinde yazılmıştır. Biz bu şekilleri olduğu gibi almayı uygun bulduk, zira bu şekillerde arkaik bir ek olduğunu düşündük. Tamlananın sonundaki ekin de biz yönelme eki yerine bir acıma ünlemi olabileceğini düşünüyoruz. Benzer yapı Yenisey Bölgesi Eski Türk yazıtlarında da görülür: äsizim-ä (Şirin 2016: 293-294, 662 vd.) äsiz, sık sık I. teklik iyelik ekiyle çekime girer: äsiz+im. TEZCAN, Yenisey mezar taşlarındaki bökme- 'doymamak, bıkıp usanmamak' eylemini semantik açıdan bu dizelerdeki eylemlerle karşılaştırır (Şirin 2016: 161). Kanımızca metinlerde nadir gözlemlediğimiz bu yapı Dede Korkut'un yazılı metnin en eski tabakasındaki arkaik bir zarf-fiile işaret etmektedir. Bu yapı aynı zamanda Azerbaycan Türkçesindeki \{-mIş\} ekinin bugün zarf-fiil gibi kullanımını hatırlatıyor. Krş. \{-mAdIn\} için Ergin 2009/II: 468.

7 Üstünova 1998: 177; Daşdemir 2001: 66.

8 Yazmada küçüm okunacak şekildedir. 


\section{J(৫)}

Qulag̉umda şuşayan ${ }^{9}$ nāyibüm-misin?

Béşikde qoyub gétdügüm qardaşçug̉um-mısın? (Drs.136b/1-3) Krş. Drs.136b/9-10 benzer şekildedir.

"Kaytabanım (kaytabandan develerimi) güden kervanbaşım mısın? Kazaguçım/Kazaguç (atlarımı) güden yılkıcım mısın? Ak ağılım (Ak ağıldan) koyunlarımı güden çobanım mısın? Kulağımda fısıldayan naibim misin? Beşikte bırakıp gittiğim kardeşç̧̧̆im misin?"

Kimi örneklerde, bu birleşik zarf görünümünde olan birimler, her iki şekilde anlaşılabilir. Manzum tarzdaki bu dizelerin devamında $\{-A n\}$ yanı sıra $\{-$ iken\}'li zarf-fiilli yapıların takip etmesi bize bunu düşündürüyor, ancak burada yazıcının önceki metin üzerinde sonradan değişikliğe gittiği de düşünülebilir (dürtüşende yerine!), sonra takip eden dizedeki sıfat-fiil tamlaması (hak yandıran çırag) bunu destekler niteliktedir:

Çalışan-da qara polat uz qliıcuy gédilmesün!

Dürtişür-iken ala gönderüy uvanmasun!

$\cdots$

Haq yanduran çıraġuy yana țursun! (Drs.19b/6-7, 9)

"Çaldığında (çalan) kara polat uz (keskin!) kılııın gedilmesin! Dürtüşürken ala gönderin parçalanmasın! Hak yandıran/Hakkın yandırdığı çırası (çıran) yana dursun!” Krş. 35a/4-5, $79 a / 9)$.

Dede Korkut'un girişinde yer alan başka bir metinde geçen her iki anlamı ifade edebilen yapıdaki zarf-fiilli ve tamlamalı örneklere bakalım:

Ayne güni okıyan-da ${ }^{10}$ quṭbe görklü

Kulak urup diyleyen-de ümmet görklü.

Minarede baylayan-da fakı görklü

Dizin basup oturan-da helāl görklü

Dulumından ağarsa baba görkli

Ag südin țoya emzürse ana görkli.

9 ÖzçELiK, Kaşgarl1'da geçen şuwşaş- 'fisıldaşmak', şuwşat- 'fisıldamak' ve sufşa- 'fisıldamak' fiillerinden hareketle şimdiye dek şorşa-/şarşa- gibi okunan kelimeyi ilk defa şuşa- 'fisıldamak' olarak okumuştur. (2016/I: 814-815)

10 ÖzçELiK, okıyanda > okınanda şeklinde tamir etmiştir. 
Yanaşup yola giren-de qara bağı1 ${ }^{11}$ görklü.

Sevgili qardaş görkli. (Drs.5a/10-11, Drs.5b/1)

"Cuma günü okunan / okununca hutbe güzel(dir)! Kulak verip dinleyen/dinleyince ümmet güzel(dir)! Minarede banlayan/banlayınca müezzin/fakih güzel(dir)! Dizini basip oturan\{oturunca eş/helal, güzel(dir)!" Dulumundan ağarırsa baba güzel(dir)! Ak sütünü doya(sıya) emzirirse anne güzel(dir)! Yanaşıp yola giren/girince kara bağır, güzel(dir)! Sevgili kardeş ne güzeldir!"

Yukarda takip eden dizelerde alternatif olarak $\{$-sA $\}$ zarf-fiilinin gelmesi buradaki yapının zarf-fiil gibi anlaşılmasını desteklemektedir. Dizelerin sonundaki görklü isim soylu yüklemdir.

Aşağıda sıfat-fiilli kelime grubu olduğunu düşündüğümüz örneklere yer verildi:

Alar șabāh șapa yérde dikilen-de ag̉-ban évlü

Atlas-1la yapılan-da gök șayvanlu

Tavla tavla çekilen-de şahbaz atlu

Çağıruban dad véren-de b/yol ${ }^{12}$ çavuşlu

yaykanduġında yaǵ dökilen bol ni'metlü̈ ${ }^{13}$

11 Bir başka yeni okuyuş takip eden dizeye istinaden bugra şeklindedir. Sanırım son dizeden önce başka bir dize gelmeliydi.

12 Metinde yol okunacak şekildedir. TEZCAN-BOESCHOTEN ve ÖzçELiK: yol. Kanımca bol okuyuşu daha doğrudur: Çağırdığında yardıma koşan bol çavuşu olan (...) Han Uruz'un babası Han Kazan! Kimi durumlarda Farsçada ortak deyimler ya da alınma kopyalar bize ipucu verebilir: Krş. dād kardan/zadan Almanca um Hilfe schreien, um Hilfe rufen 'yardım istemek, yardıma çağırmak' (Junker-Alavi 1988: 121); dād kardan '1. haykırmak, çığırmak; 2. adaleti yerine getirmek, hakkı almak' (Gholkarian 2000: 89). dad-e kesi-rā dādan 'hakkını istemek, birini haklı tanıtmak' (Gholkarian 2000: 95). Metnin dize sıralamasında kelime anlaşılmadığından okuyana bu sıralamadaki dize ters gelebilir. Bu durumda dize şöyle de anlaşılabilir: "Çağırdığında hakkını veren/diğinde bol/yol (?) çavuşu olan".

13 Bk. Özçelik 2016/I: 895-896. ÖzçELiK, eksik olduğu düşünülen bu dizeyi sofrasinda olarak tamir etmiştir ve şöyle açıklamıştır: "Sofrası serildiğinde yağ dökülen bol nimetli". Bizim tamirimiz ise yayıldığında/çalkalandığında yağı bol dökülen şeklindedir. Çünkü yağ yayıkta yayılır, sofra ise çekilir ya da yaz/yılır. ALıșiK da bizim gibi bağlama uygun olarak sofra yerine eksik kelimenin yayık okunabileceğini önermiş̧ir: yayık yayıldığında yayığından yağ dökülen (taşan) bol nimetlü (2002: 161). ÖzçELiK, yağ dök(il)fiilini Süheyl ü Nevbahar'da geçen xo:n dökil- şekline dayanarak 'sofra açmak, ziyafet vermek' olarak düşünmüş, ancak biz buna katılmıyoruz (2016/I: 497-498). Sofranın bol yağlı olması o sofranın kanımca zengin olduğuna işarettir. Bol yağ yemeklerde bilindiği gibi lezzet katar. 


\section{J(৫)}

qalmış yiğit arxası

Han Uruz'un babası Xanum Qazan! (Drs.56b/12-13, Drs.57a/1-6) Ayrıca krş. Drs.104a/12; Drs.104b/2 ve Vat.79b/7-9; Vat.101a/3-5.

Burada dikkat edilirse hitap edilen, dolayısı ile tamlanan dizelerin sonundaki kişi Xan Qazan'dır. Bu durumda metin en doğru şu şekilde çevrilmelidir:

"Alaca sabah, sapa yerde dikilen ak-ban evi olan (evli), atlas ile örtülen (örtülmüş) gök gölgeliği olan (sayvanlı), tavla tavla çekilen şahbaz atları olan (atlı), çağırdığında imdada yetişen bol çavuşu olan (çavuşlu), (yayık) yayıldığında yağı dökülen bol nimeti olan (nimetli), (öksüz) kalmış yiğidin arkası (...) Han Uruz'un babası Han'ım Kazan!”

Kimi örneklerde ekin zarf-fiil mi yoksa sıfat-fiil mi olduğu belirsizdir. Metinde hem olumsuz \{-mAyAn\} sıfat-fiilli hem de zarf-fiilli şekilleri karışık. Giriş kısmının sonradan eklendiği de hesap edilmelidir, çünkü giriş bölümündeki şekilleri hikâye metinlerine göre zarf-fiil kullanımı açısından dikkat çekicidir, örneğin $\{-$ InCA\}:

Ata adın yortmayan xoyrad og்ul,

Ata bélinden énince énmese yég.

Ana rahmine düşünce țog̀masa yég.

Ata adın yorıdan-da ${ }^{14}$ devletlü oğul yég (Drs.4a/9-11)

"Ata adını yaşatmayan hoyrat oğul/ata belinden ineceğine/ininceye dek inmese/inmesin (daha) iyi! Ana rahmine düşeceğine/düşünceye dek doğmasa/doğmasın (daha) iyi! Ata adını yaşatan/yaşatınca devletlü oğul (daha) iyidir!"

Daha ilk dizede, $\{-A n\}$ sifat-fiilinin olumsuzu \{-mAyAn\} şeklini görürken dördüncü dizede $d A$ edatı görülür. Her iki dizede de de dikkat edilirse aynı atasözü söz konusudur. Biri olumlu biri olumsuzdur: ata adını yaşatmayan ve ata adını yaşatan! (yorıtmayan ve yorıdan-da). Bu örnekte ekin birleşik bir zarf-fiil eki olamayacağı açık ve nettir. Aşağıdaki örnek te (sığmayan) tar ağızlum sıfat-tamlama grubu buna dayanaktır. Sonuncu dizedeki devletli kelimesi ise vezne uymadığından, yazıcı tarafından eklenmiş olmalıdır.

14 Kanımızca bugüne dek yörüdende okunan kelime Eski Uygurca yorıt- 'yaşatmak' fiili ile bağlıdır. Bu da metinde arkaik bir özellik taşıyan ilginç bir kelimedir. Metnin bağlamına da ayrıca uygun düşer. 


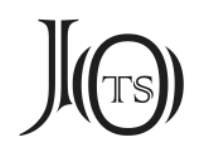

Aşağıdaki dizelerde, Kanlı Koca Oğlu Kan Turalı hikâyesinin, Oğuz alp yiğitlerinden Kanturalı, Trabzon tekürünün kızı Selcen Hatun'u şu söz ve benzetmelerle övmektedir:

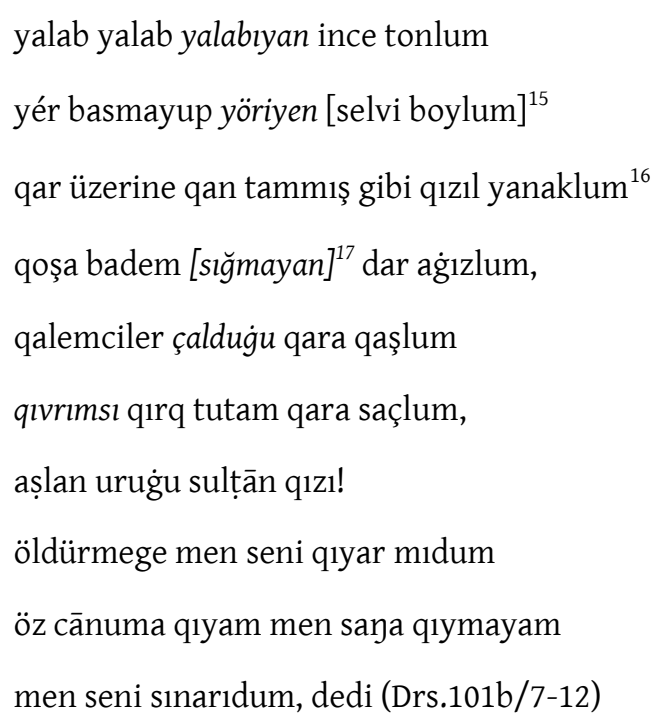

Bu dizelerde birçok sıfat-fiilli ve zarf-fiilli yapı bir arada görülmektedir. Dizelerin durak ve vezin ölçüsü burada bir-iki dize dışında uyumlu gözükmektedir: $4+3+4=11$ durak ve vezinli. Tamlanan burada arka arkaya takip eden dizelerin en sonunda, övülen sevgili 'aslan uruğu sultan kızı'dır. Dede Korkut Kitabı'nda kişi adlarının en dikkat çekici bir yönü de önemli kahramanların uzun epitetlerle tanıtılmasıdır.

Yukarda tammış gibi zarf tümleci ise yazıcının tasarrufunda yapılan bir değişiklik görünümü vermektedir, çünkü bunun taman-da gibi bir yapı olması beklenirdi.
ag̉ ban évüm dikilen-de yurdı qalmış
qarıcuq anam oluran-da yéri qalmış
og̉lum Uruz ox atan-da puta qalmış

15 Tamir, Vat.61a/3 ve Drs.8a/9 ve bağlama göre yapıldı.

16 Başka örnekte al yanak (Drs.8a/8-11) şeklindedir. Yazıcının dizeyi al yerine kızıl olarak ayrıca \{-An\} sıfat-fiilini '-mış gibi' (< kar üzerine kan taman kızıl yanaklum yerine) şeklinde değiştirdiğini düşünmekteyiz. Gibi yanında $\{$-sI $\}$ ekinin kullanımı da burada dikkat çekicidir.

17 Tamir, Vat.61a/4 ve Drs.8a/10 ve bağlama göre yapıldı. 


\section{J(৫)}

og̉uz bégleri at çapan-da meydān qalmış

qara mudbaq dikilen-de ocaq qalmış (Drs.24a/7-10)

"Ak ban evimin dikildiği yurdu/izi kalmış, yaşlıca anamın oturduğu yeri(n) izi kalmış. Oğlum Uruz'un ok attığı pota kalmış. Oğuz beylerinin at koşturduğu meydan kalmış. Kara mutfağın dikildiği ocak kalmış"

$d A$ edatı örneklerde daha çok vurgu işlevindedir. Bu ifadeler dikkat edildiğinde hep manzum kısımlarda geçmektedir ve onun işlevini dil içi değil, müzikaliteyi (ritim, ahenk, durak vb.) ilgilendiren dil dışı sebeplere dayandırmak gerekir. BORATAV da bu edata -özellikle müzik eşliğinde icra edilen halk edebiyatı ürünlerinde, bir dolgu malzemesi gibi çok sık başvurulduğunu belirtmektedir. (Boratav 1983: 338; Daşdemir 2001: 67).

Dede Korkut Kitabı'nda kahramanlar 'soylamalarını hep kopuz eşliğinde icra ederler. Bundan dolayı $d A$ edat 1 bir ritim unsuru olarak söz konusu sıfat-fiil gruplarının üzerine getirilmiş olmalıdır. Bk. Daşdemir 2001: 67.

Daha eski, arkaik bir yapı olduğunu düşündüğümüz şu sıfat tamlamasında dA ekine gereksinim duyulmamıştır. Burada tamlayan durum eki de yoktur:

Qızlar oturan otaġa geldi (Drs. 58a/2-3) "Kızların oturduğu otağa geldi."

Okunması güçlük çıaran kelimelerden biri de şu dizedeki kelimedir, ancak bu dizede sıfat-fiilli bir tamlama söz konusu değildir:

Bağır gibi uyunan-da yoġurtdan ne var? (Drs.54b/7)

Bu dizedeki kelime ÖzçELiK tarafından buğurki (ögüninizde) ‘şimdiki, bu seferki' (TEZCAN, benir gibi ügininde okunsa da o bunu ögininizde şeklinde okumayı teklif etmektedir (2016/I: 474-475, II: 217).

\section{4. \{-ArdA\} Zarf-Fiili mi Yoksa \{-Ar\} Sıfat-Fiili + dA Edatı mıdır?}

Üzerinde duracağımız bir başka ek te Dede Korkut'ta arkaik olduğunu düşündüğümüz \{-ArdA\} ekidir. Bayraktar, Eski Anadolu Türkçesi döneminde yalnız Dede Korkut'ta bu ekin geçtiği belirtir (2004: 252-254). Ancak, bu ek Eski Anadolu Türkçesinden başka metinlerde de görülür. Bk. Demirbilek 2017: 297-302. 


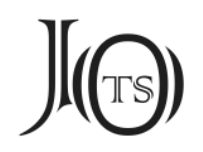

Bu ek de \{-AndA\} gibi oluşan zarf-fiil eklerinden biridir. Geniş zaman sıfatfiil eki ile bulunma durum ekinin kalıplaşması sonucu oluşan bu zarf-fiil eki, ${ }^{18}$ Harezm Türkçesi döneminde ortaya çıkmış, Karahanlı Türkçesi ve Kıpçak Türkçesine ait eserlerde de $\{-\mathrm{Ar}\},\{-\mathrm{Ur}\},\{-r\}+$ iyelik eki + dA şeklinde karşımıza çıkmaktadır. Çağatay Türkçesinde pek sık olmasa da uzun yıllar kullanılmıştır. Bugün de Yeni Uygur Türkçesinde yaygın olmasa da kullanımı devam etmektedir. $B u$ ve daha sonraki dönem eserlerinde zamanda eşitlik zarf-fiili oluşturan bu ek, Türkiye Türkçesi “-IncA, -ken, -dIktA, -dIğIndA, -dIğI zaman” zarf-fiil eklerini karşılar. \{-Ar-dA\} sifat-fiiline daha 1952'de Rossi dikkati çekmişti. O, uçar-da (ayrica qalarda ve qoparda da olduğu gibi) ${ }^{19}$ kelimesindeki da ekini zarf-fiilden ayrı olduğunu göstermek için - işareti ile ayırmıştı. Ayrıca zarf-fiilli şekiller altında \{ArDA\} ekinin XV. asırda kullanılan bir şekil olduğuna işaret etmiştir: ${ }^{20}$

Bütün metinde bu ekin Tepegöz'de qalar ve qopar şekillerinde geçtiğini gözlemliyoruz:

qalar-da qopar-da yiğit yérün ne yérdür? (Drs.117b/6) "Yaşadığın, doğduğun yer, yiğit neresidir?".

qalar-da qopar-da yérüm Gün (Ortaç?) (Drs.117b./11) "Yaşadığım, doğduğum yer Gün Ortaç(tır)".

qalar-da qopar-da yérün sorar olsam ne yérdür? (Drs.136a/9-10) "Yaşadığın, doğduğun yerini soracak olursam neresidir?"

Yukardaki her iki dizede de kelimeyi zarf-filli olarak düşündüğümüzde metnin anlamı bozulmaktadır. Hâlbuki kelime bir sıfat-filli/partisipli tamlama grubu

18 Bu zarf-fiil eki en eski tarihli eser olarak Mu'inü'l-Mürid'de görülmektedir (Toparlı 1988). Kısasü'l-Enbiyâ'da, $\{-r\},\{-A r\},\{-U r\}$ eki iyelik ve bulunma durumu eki alarak zaman gösteren ulaç görevinde kullanılmaktadır (Ata 1997: 86). Doğu Türkçesi veya Çağatay Türkçesi ile ilgili diğer eserlerde bu zarf-fiil ekinden bahsedilmemektedir (Eckmann 1988). Ali Şir Nevayî̀nin Sedd-i İskenderi isimli eserinde krş. çıkarda yoluktı manga rûberû (Eckmann 1963: 51-63).

19 Rossi'nin bu örneği ancak zarf-fiil değil, bir yer tümleci/zarf tümlecidir. Bk. Gördi-kim uçar-da quzġun [qalmış], tazı țoluşmuş, yurtda qalmış (Drs.24a/3-4); Gördiler kim uçar-da quzġun qalmış, tazı țoluşmuş, yurtda qalmış (Drs.47b/2-3).

20 Altay metinlerinde kelerde ve kalarda, ARAT neşrinden ise (mısra 1578) ölürde örneğini vermiştir (Rossi 1952: 263). 


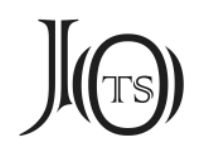

olarak ele alındığında metnin bağlamına uygun olduğu görülür. Bu ekin Dede Korkut metninin daha eski bir nüshasından kalma bir iz olması da mümkündür. Dolayısı ile $d A$, burada da vurgu işlevinde bir edattır.

ERGiN, yukardaki (Drs.117b.6) dizeyi şöyle çevirmiştir: "Memleketten doğum yerinden yiğit yerin neresidir?”. GÖKYAY, "Kalkıp meydana çıtı̆̆ında yiğit, yerin nedir?". ÖzçELiK ilgili dizeleri “Yiğit sen nerelisin? ve "Yaşadığım yer gün ortası" diye parantez içinde göstermiştir. (2016/II: 734, 754). Kanımızca bütün araştırmacılar verilen anlama yakın açıklamada bulunmuşlardır.

TEZCAN'in yukardaki bu üç örnek dizede geçen ikileme ile ilgili tereddütlü yorumu ise ilgi çekicidir. Onun bu tereddüdü kal-filinin sonundaki $\{-\mathrm{Ar}\}$ ortac1dır. Fiil ek alacaksa $\{$-ur\}/\{-Ir\} olması beklenirdi. Başka bir alternatif olarak ise kalkar kopar olmak deyimindeki fiiller de eşanlamlı ikileme görünümündedir, görüşüne kanıt olarak da şu dizeyi gösterir:

qardaşlu yiğitler qalkar qopar olur

qardaşsuz miskin yiğit ensesine yumruq toqınsa,

ağlayuban dört yanına baqar olur (Dr.131b/8)

ERGiN ve GÖKYAY, bu dizedeki deyimi olduğu gibi aktarmışlardır. ÖzçELiK ise, deyimi sözlükte 'özgüveni yüksek olmak' olarak vermiş ve dizeyi: "Kardeşli yiğitlerin özgüveni yüksek olur” şeklinde serbest çevirmiştir. (2016/I: 802)

Kanımızca TEZCAN'ın tereddüt ettiği kal- 'yükselmek' olarak ele aldığı bu fiil deyimde gerçek anlamını bulmaktadır, zira Türkiye Türkçesinde de kal- ve kalkfiilleri anlam ayırt edicidir. Biri hareketsizliği ya da 'yaşamak, varlığını sürdürmek' anlamlarını ifade ederken diğeri $\{-k-\}$ eki ile yükselmeyi, yani yerinden kalkmayı anlatır.

TEZCAN, Notlar dizininde bu dizelerdeki qal-/qop-ve qalk-/qop- fiillerini eşanlamlı ikilemeler olarak göstermiş ve ikisine de aynı anlamı vermiştir (2001: 411), ancak söz konusu dizelerdeki bu anlamlandırma, ERGiN ve GöKYAY'da olduğu gibi metnin bağlamına uygun düşmemektedir.

ÖzçELiK'in yukardaki dizelerdeki ikilemeyi bir tamlama (qalar qopar yér 'oturup kalkılan, hayat sürülen yer, yani ikamet edilen yer') gibi ele alması bizim düşüncemizi desteklemektedir, zira bu durumda yukardaki üç dizede geçen qalar- 


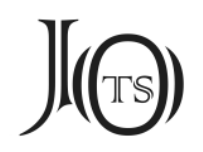

da qoparda yér bir sifat-tamlama grubu teşkil etmektedir. Yani her iki kelimede geçen \{-Ar\} bir geniş zaman sıfat-fiilidir, bitişik yazılan 'da' ise bir vurgu edatıdır. (2016/I: 738-739).

Günümüzde kop- hala 'kalkmak, çıkmak' anlamında kullanılmaktadır, kop gel gibi. Bundan ötürü biz buradaki dizeyi metnin bağlamına göre 'yerinden duramayan, hareketli' olarak düşünmekteyiz. Böylece ilk dizeyi, "Kardeşli yiğitler yerinde duramaz" gibi de aktarmamız mümkündür.

Rossi, metinde geçen sıfat-fiiller bahsinde ayrıca aqarl-da ve biterli-de şekillerine de dikkati çekmiştir (1999: 261), aqarl 'akan', biterli 'biten, yeşeren':

aqarlı-da [șularına] ${ }^{21}$ qarǵamağıl,

qaẓılıq țag̉ınun șuçı yoqdur.

biterli-de otlarına qarġamaġıl,

qaẓlıq țag̉ınuy șuçı yoqdur.

qaçar géyiklerine qarğamağıl,

qaẓılıq țaġınuy günahı yoqdur (Drs.16a/5-7).

qaẓılıq țaǵ!!

aqar senüy șularuy,

aqar iken aqmaz olsun!

biter senüy otlaruy,

aiter iken bitmez olsun!

qaçar senüy géyiklerüy,

qaẓılıq țağı!

qaçar iken qaçmaz olsun, țaşa dönsün! (Drs.15b/8-10.)

Paralel dizede geçen qaçar geyik şekli bize burada kelimenin asıl şeklinin s1fat-fiil olduğuna işaret etmektedir. Ayrıca oğlunu aramaya çıkan annenin Kazılık dağına yaptığı kargışında geçen benzer dizeler de düşündürücüdür, zira bunlarda doğrudan \{-Ar\} sıfat-fiilli şekilleri görülür. Oğlanın daha sonra annesine cevap verdiği dizelerde ise (bk. yukarda Drs.16a/5-7) beklentinin aksine aykırı bir

${ }^{21}$ Metinde aqar ide okunacak şekildedir. ÖzçELiK, paralel dizede otlarına olduğu için bu dizede șularına eklenmesini gerektiğini belirtmektedir. Ayrıca Vat. 65a/13'te aqarll-da ve biterli-de şeklinde yazılmıştir. (2016/I: 300) 


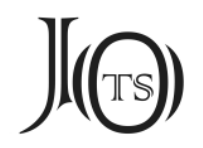

şekille karşılaşılır. ( $\{-\mathrm{Ar}\}$ yerine $\{-\mathrm{Arl} 1-\mathrm{dA}\})$. Bunu yazıcı tarafından yazılmış bir çekimleme hatası ya da vezin gereği sıfat-fiile getirilen bir ek olduğunu sanıyoruz: akar+li su ve biter+li ot (akar su ve biter ot yerine).

Bundan başka aşağıdaki örnekte, \{-Ar\} sıfat-fiilinin, sıfat-fiil tamlamasında kullanıldığı görülmektedir. Burada yine vezin gereği muhtemelen sığmaz yerine sığmayan tercih edilmiştir:

qurılu yaya benzer çatma kaşlum

qoşa badem sığmayan tar ağızlum

güz almasına benzer al yanaklum (Drs.8a/9-10)

\section{5. \{-dUkdA\} Zarf-Fiili mi Yoksa \{-dUk\} Sıfat-Fiili + dA Edatı mı?}

ERGiN, \{-dUkdA\} ekini, \{-AndA\} ekinde olduğu gibi Dede Korkut Kitabi'nda, gerundium grubu altında, sıfat-fiilin zarf-fiilleşmesi olarak görmektedir (2009/II: 469, 476). \{-dUkdA\} eki, yapısından anlaşılacağı gibi $\{$-dUk\} sıfat-fiil eki ve $\{+\mathrm{dA}\}$ bulunma durum ekinin kalıplaşması ile oluşmuştur. Eski Anadolu Türkçesinde ekin yuvarlak şekli görülmektedir. Orhun Türkçesinde ek, çok ilginçtir ki iyelikli olarak da görülür..$^{22}$ Ek zaman zarfi olarak kullanıldığında yüklemin meydana geldiği zamanı bildirir ve eklendiği fiile '-dığı zaman' anlamını katar. KAçALìn, Dede Korkut'un Vatikan nüshasının Dresden'e göre daha eski olmasından bahsederken, Vatikan nüshasında geçen \{-dUkdA\} zarf-fiili yerine Dresden nüshasında \{-AndA\} şeklinin geçmesini, yapı bakımından ayırt edici bir özellik gibi göstermektedir. Bunun için de aşağıdaki dizeyi örnek vermiştir (2016: 15). Ancak Dresden'de her iki ekin de karışık kullanıldığını belirtmeliyiz:

Ox atanda men senüy oxuy1 yarmadum mı? "Ok atınca ben senin okunu yarmadım mı?" (Drs.60a/9-10); Oq atduqda senüy oquy geçmedüm mi? "Ok atınca ben senin okunu geçmedim mi?" (Vat.82a/6); Saqalı uzun tat eri bapladuqda (...) "Sakalı uzun tat eri ezan okuduğunda (...)" (Drs.7b/2-6).

${ }^{22}\{$-dUKdA\}, Eski Türkçeden beri bulunma durumu ekinden önce özneyi belirten iyelik eki de alabilmektedir: eçim qagan ili kamşag boltukınta bodun ilig ikegü boltukınta izgil bodun birle süyüşdümiz "Amcam kağanın ülkesi kargaşalı olduğunda, halk ve hükümdar ayrılı̆̆a düştüğünde İzgil halkı ile savaştık." (Köl Tigin, Kuzey 3); qayım türk bilge kagan olurtukınta (...) "Babam Türk Bilge Kağan tahta çıktığında (...)" (Bilge Kagan, Güney 13-15), (Şirin 2015: 99). 


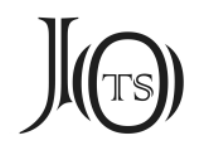

Dede Korkut metninde geçen bir başka kelime oldukça tartışmalıdır. İyelik eksiz olan bu şekil, metnimizin erken nüshalarındaki arkaik bir şekil olmalıdır:

Gitdük-de yérüy otlaqların geyik bilür.

Genez ${ }^{23}$ yérler çemenlerin qulan bilür

Ayru ayru yollar izin deve bilür (Drs.4b/2; Vat.59b/1)

Yédi dere ġoxuların dilkü bilür. ${ }^{24}$ "Gitttiği yerin otlaklarını geyik bilir."

ERGIN, GÖKYAY ve TEZCAN, ilk dizedeki şekli gitdükte olarak okurken, TEZCAN okuyuşta tereddüt etmiştir. o gétdükde şeklinin her iki nüshada da (Dresden ve Vatikan) metne uymadığını ve eski bir çekimleme yanlışı olduğunu ya da eksik bir kelime olduğunu söylerken gedikte okuyuşu yerine yazılmış da olabileceğini ve kesin bir çözüm öneremeyeceğini söyler. TuLUM ve ÖzçELik ise gedükde yér okuyuşunu uygun bulmuştur (2016/I: 165-166). Gedük okuyuşunu destekleyen başka yazarlara değinmeden biz kelimenin sıfat-fiil tamlaması (gétdük yér) şeklinde alındığında bağlamın korunduğunu düşünmekteyiz. Ayrıca kelime Vatikan nüshasında da harekeli olarak gitdük-de şeklinde yazılmıştır. TULUM ve ÖzçELIK'i kanımızca $\{$-AndA\} zarf-fiili görünümündeki $\{-\mathrm{An}\}$ sıfat-fiili ve bitişik yazılan $\mathrm{dA}$ edatı yanıltmıştır.

Kısacası ERGiN ve GÖKYAY okuyuşları bizce doğru olmalıdır. ÖzçELiK, gedük okuyuşundan ötürü gétdükde şeklini dizine almamıştır (2016/II: 855).

23 Tekin, gegez 'yakın'; ÖzçELiK, kelez 'verimsiz, kıraç'.

24 İstanbul Topkapı Sarayı Müzesi, Revanköşkü Kütüphanesinde muhafaza edilen Yazıcıŏlu 'Ali’nin Tarih-i Al-i Selçuk isimli eserinde (Kırzıoğlu 2000: 85-103) bu kısım şöyledir:

burlu yonca dadın borsuk bilür yédi dere qoncasın dilkü bilür çuvaldız kıymetini nökeri bilür ağır yüküng hengini qatır bilür yédi yollar ayırdın deve bilür er ağırın er yeynisin eren bilür qara başa ağrı gelse beyni bilür géng yérler otlağın geyig bilür datlu suyung dadın kulang bilür er nakesin, er cömerdin ozan bilür (28-29) 


\section{J(৫)}

\section{1. $\{$-dUk $\}+$ İyelik Eki + DA}

Bağlamdan da anlaşılacağı üzere buradaki ekin iyelikli ve bulunma durum ekli şekli Dede Korkut'ta birçok şahısta görülmektedir, ancak burada bunun zarffiil olduğu apaçıtır. Örneğin:

Beyrek yayı gördüginde yoldaşların aydı ağladı (Drs.56b/1); Ölüm vaqtı geldüginde arı imāndan ayırmasun! (Drs.119b/2)

\section{2. $\{-$ AndA $\}$ veya $\{-\mathrm{dUg}\}+$ İyelik Eki $+\mathrm{DA}$ ve $\{-\mathrm{An}\}$ çag $+\mathrm{DA}$ ve $\{-\mathrm{An}\}$ vaqit}

Üzerinde durulması gereken önemli bir nokta da ekin gelişim seyrini takip etme açısından sıfat-fiilin iyelik eki ve edatlı kullanımlarıdır. Dede Korkut Kitabı'nda $\{-A n d A\}$ 'ya alternatif olarak $\{-A n\}$ sifat-filine çag ya da vaqt son çekim edatı ve $\{+\mathrm{dA}\}$ durum eki de getirilir. Aşağıdaki örnekte, dördüncü dizeden sonra bunu yeniden $\{-$ An $\}+$ çag + DA eki takip etmektedir.

salqum șalqum țan yélleri esdüginde

șaqallu bozac țurgay sayraduqda

bedevī atlar issini görüp 'oqraduqda

șaqalı uzun tat eri bagladuqda

aqlı qaralı seçilen ${ }^{25}$ çağda

qalın Oğuzun gelini kızı bezenen çağda

göksi gözel qaba daġlara gün degende

beg yigitler cılasunlar birbirine quyulan çağ (Drs.7b/2-6)

meger Xān'um, Qaẓılıq Qoca țutsaq oldığı vaqt bir oğlancuġı varıdı. (Drs.103b/13-104a./1)

ölülerüye aş vérdügüy vaqt elleründen aluram. (Drs.: 139a./11-12)

Anlar bir pare yédügi vaqt sen iki pāre yégil! (Vat.88b/7-8) "Onlar bir parça yediğinde sen iki parça ye!" (Kaçalin 2016: 15)

Anlar bir yédüginde sen iki yégil! (Drs.29a/1) "Onlar bir yediğinde sen iki (lokma) ye!”

Aşağıdaki örnekte diğer şekillerden aykırı $\{+$ AsI $\} /\{+A s U\}$ vaqt için bir örnek buluruz, ancak bu okuyuş kanımızca tartışmalıdır (Özçelik 2016/I: 690). \{-An\} s1fat-fiilinden sonra gelen çağ $(+d a)$ ve $\{-d U q\}$ sıfat fiilinden sonra gelen vaqt $v b$. son

25 Metinde seçen okunacak şekildedir. Drs.12b/7 ve Vat.63b/3 seçilen. 


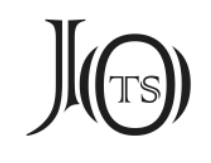

çekim edatları eki zarflaştırmışlardır. Son çekim edatı bu örneklerde $\{+\mathrm{dA}\}$ lokatif ekine alternatif bir kullanım gibi gözükmektedir:

Qarşusından ol eri șancasum ${ }^{26}$ vaqt (deyedüm?). (Drs. 105b/4)

\section{Sonuç}

Araştırmacıların da tespit ettiği gibi nazım şeklinde belirlenen dizelerde belli bir ritim, ahenk ve vezin hâkimdir. Bunda sentaktik paralelizmin etkisi büyüktür. Konumuz olan sıfat-fiilli şekiller bitişik yazımdan kaynaklı araştırmacıların okuma hatalarına neden olmuştur. Yani sıfat fiile bitişik yazılan $d A$ edatı zarf-fiile aitmiş gibi kabul edilmiştir. Anlaşılan bunda yalnız okuyucu değil yazıcının da payı var; yani yazıcı anlamadığı kimi yerlerde $\{$-AndA\} yerine alternatif olarak diğer zarf-fiilleri devreye sokmuş: $\{-\mathrm{sA}\},\{-\mathrm{iken}\},\{$-dIgIndA $\}$ vb. Metinde birleşik yazılan bu dA'lı şekiller, Dede Korkut araştırıcılarını uzun zaman yanıltmıştır. Dede Korkut metninde okunuşu tartışmalı olan bu şekilleri sadeleştirirken/günümüz Türkçesine uyarlarken -yukarda belirttiğimiz üzere- dikkatle yeniden ele almak doğru olacaktır.
Kisaltmalar
bk. = Bakınız.
Drs. = Dede Korkut kitabının Dresden yazması.
krş. = karşılaştırınız.
Vat. = Dede Korkut kitabının Vatikan yazması.

\section{Kaynakça}

Alışı, G. S. (2002). "Dede Korkut Kitabını Anlamaya Katkılar”, Türkoloji Dergisi, 15/1: $145-162$.

ATA, A. (1997). Kısasü'l-Enbiya (Peygamber Kıssaları) I-II, Ankara: Türk Dil Kurumu Yayınları.

26 Metinde sançtum okunacak şekilde. ÖzçELiK: Vat.101b/10 ve bağlama göre sancasum. Arap alfabesi ile $d y d m$ 


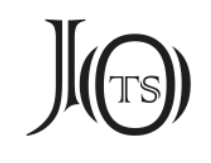

BAYRAKTAR, N. (2004). Türkçede Fiilimsiler, Ankara: Türk Dil Kurumu Yayınları.

BoratAV, P. N. (1983). "Halk Türkülerine Dair", Folklor ve Edebiyat II, Adam Yayınlar1, İstanbul: 337-339.

DAŞDEMIR, M. (2001). “Dedem Korkut Kitabında /(y)An+da/ Zarf Fiil Ekinden Farklı Olarak /(y)An/ + /da/ Yapıları", Atatürk Üniversitesi Türkiyat Araştırmaları Enstitüsü Dergisi, 17: 61-67.

DemirbíleK, S. (2017). “-rdA/-(X)rdA Zarf-fiil Ekinin Tarihî ve Çağdaş Türk Lehçelerinde Kullanım Biçimleri”, Vefatının 20. Yılı Münasebetiyle Prof. Dr. Necmettin HACIEMiNoĞLU Hatıra Kitabı, Eds. A. İ. ÖBEK et al. Türk Edebiyatı Vakfı Yayınları, İstanbul: 297302.

ECKMANN, J. (1963). “Çağataycada İsim-Fiiller”, Türk Dili Araştırmaları Yıllığı Belleten 1962: 51-60.

EcKMANN, J. (1988). Çağatayca El Kitabı, İstanbul: İstanbul Üniversitesi Edebiyat Fakültesi Yayınları.

ERGiN, M. (2009). Dede Korkut Kitabı I-II, Ankara: Türk Dil Kurumu Yayınları.

GHOLKARİAn, G. (2000). Türkçe-Farsça ve Farsça-Türkçe Sözlük, Tebriz.

JunKeR, H. F. J. \& B. Alavi (1988). Wörterbuch Persisch-Deutsch, Leipzig: Verlag Enzyklopädie.

KAçALin, M. S. (2016). Oğuzların Diliyle Dedem Korkud'un Kitabı, Ankara: Türk Dil Kurumu Yayınları.

KiRzıoĞLU, F. (2000). Dede Korkut Oğuznameleri, Ankara: Atatürk Kültür Merkezi Yayınları.

KudRET, C. (1980). Bugünkü Türkçemizle Dede Korkut Hikâyeleri, 6. Bask1, İstanbul: Varlık Yayınları.

MiYASOĞLU, M. (1999). Dede Korkut Kitabı, 3. Baskı, İstanbul: Akçă̆ Yayınları.

ÖzçELiK, S. (2016). Dede Korkut: I. Dresden Nüshası, Giriş, Notlar; II. Metin, Dizin, Ankara: Türk Dil Kurumu Yayınları.

Rossi, E. (1952). Il 'Kitab-i Dede Qorqut': racconti epico-cavallereschi dei Turchi Oguz tradotti e annotati con 'facsimile' del ms. Vat. turco 102, Città del Vaticano: Biblioteca apostolica Vaticana. 


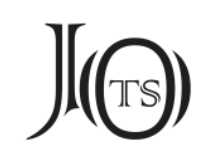

Rossi, E. (1999). “Dede Korkut Kitabı Üzerine Araştırma”, Çev. M. H. ŞAKíRoĞLU, Erdem, 12-34: 183-276.

Şíín, H. (2015). Kül Tigin Yazıtı, Notlar, İstanbul: Bilgi Kültür Sanat.

Şíin, H. (2016). Eski Türk Yazıtları Söz Varlı̆̆ı İncelemesi, Ankara: Türk Dil Kurumu Yayınları.

Tezcan, S. \& H. Boeschoten (2001). Dede Korkut Oğuznameleri, İstanbul: Yapı Kredi Yayınları.

TEZcAN, S. (2001). Dede Korkut Oğuznameleri Üzerine Notlar, İstanbul: Yapı Kredi Yayınları.

TOPARLI, R. (1988). Şeyh Şeref Hace: Muinü'l-Mürid, Erzurum: Atatürk Üniversitesi Fen-Edebiyat Fakültesi Yayınları.

ÜstüNER, A. (2000). Anadolu Ağızlarında Sıfat-Fiil Ekleri, Ankara: Türk Dil Kurumu Yayınları.

ÜstÜNovA, K. (1998). Dede Korkut Destanı ve Cümleden Büyük Birlikler, İstanbul: Alfa Yayınları.

ZeYnalov, F. \& S. Elizade (1988). Kitabı Dede Gorgud, Bakı: Yazıçı. 